Çukurova Üniversitesi Mühendislik Mimarlık Fakültesi Dergisi, 33(3), ss. 101-112, Eylül 2018

Çukurova University Journal of the Faculty of Engineering and Architecture, 33(3), pp. 101-112, September 2018

\title{
Fenolün Sulu Çözeltiden Düşük Maliyetli bir Nano Kompozit ile Giderimi
}

\author{
Fatma Elçin ERKURT ${ }^{* 1}$, Behzat BALCI ${ }^{1}$ \\ ${ }^{1}$ Çukurova Üniversitesi, Mühendislik Fakültesi, Çevre Mühendisliği Bölümü, Adana
}

Geliş tarihi: 16.03.2018 Kabul tarihi: 15.10 .2018

\section{$\ddot{O} z$}

$\mathrm{Bu}$ çalışmada, Eucalyptus camaldulensis kabuğu/maghemit (ECMC) kompoziti sulu çözeltiden fenol gideriminde düşük maliyetli bir adsorbent olarak kullanılmıştır. ECMC'nin yapısal karakterizasyonu, morfolojisi ve elementel analizleri taramalı elektron mikroskopisi (SEM), enerji dağılımlı X-1şını (EDX) ve X-1şını kırınımı difraktometresi (XRD) ile gerçekleştirilmiştir. Adsorpsiyon süreci üzerine temas zamanı, pH, sıcaklık ve başlangıç fenol konsantrasyonu gibi çeşitli parametrelerin etkisi araştırılmıştır. Yapılan çalışmalar ECMC'nin adsorpsiyon kapasitesinin fenol konsantrasyonunun artmasıyla arttığını göstermiştir. ECMC tarafından fenol gideriminde optimum $\mathrm{pH}$ 'in 5 olduğu bulunmuştur. $500 \mathrm{mg} / \mathrm{L}$ fenol için adsorpsiyon kapasitesi; 1 gram ECMC dozu ile $\mathrm{pH} 5$ 'de ve $20^{\circ} \mathrm{C}$ 'de $90,92 \mathrm{mg} / \mathrm{g}$ olarak bulunmuştur. Langmuir izotermi adsorpsiyon sürecini 0,998 korelasyon katsayısı ile mükemmel bir şekilde tanımlamıştır.

Anahtar Kelimeler: Eucalyptus camaldulensis, Adsorpsiyon, Fenol, Maghemit

\section{Removal of Phenol from Aqueous Solution by a Low-Cost Nano Composite}

\begin{abstract}
In the present study, Eucalyptus camaldulensis bark/maghemite composite (ECMC) was used as a lowcost adsorbent for the removal of phenol from aqueous solution. The structural characterization, morphology and elemental analysis of ECMC were performed by scanning electron microscopy (SEM), energy-dispersive X-ray (EDX), and X-ray diffraction (XRD). The effects of various independent parameters such as contact time, initial phenol concentration, temperature, $\mathrm{pH}$ on adsorption process were investigated. It was found that the adsorption capacity of ECMC increases with the increasing of phenol concentration. The optimum $\mathrm{pH}$ was found to be 5 for the removal of phenol by ECMC. The adsorption capacity for $500 \mathrm{mg} / \mathrm{L}$ phenol was found to be $90.92 \mathrm{mg} / \mathrm{g}$ with $1 \mathrm{~g} \mathrm{ECMC}$ at $\mathrm{pH} 5$ and $20{ }^{\circ} \mathrm{C}$. Langmuir isotherm model described perfectly the adsorption process with 0.998 correlation coefficient.
\end{abstract}

Keywords: Eucalyptus camaldulensis, Adsorption, Phenol, Maghemite

*Sorumlu yazar (Corresponding author): Fatma Elçin ERKURT, eerkurt@cu.edu.tr 


\section{GíRiș}

Artan nüfus ve gelişen teknolojinin bir sonucu olarak, çevrede toksik olabilen kirleticilerin miktar ve çeşitliliği artış göstermektedir. Özellikle sucul ortamlardaki canlılar ve halk sağlığı için önemli derecede tehdit oluşturan fenol ve bileşikleri su kaynakları için potansiyel kirleticiler pozisyonundadır. Dünya genelinde yılda yaklaşık 6 milyon ton fenol üretimi yapılmaktadır [1]. Fenol ve türevleri rafineri, petrokimya, kok ve kömür işleme atıksuları vasıtasıyla sucul ortamlara ulaşmaktadır [2]. Fenol konsantrasyonu, rafineri endüstrileri atıksularında $500 \mathrm{mg} / \mathrm{L}$ 'ye, petrokimya endüstrileri atıksularında $1200 \mathrm{mg} / \mathrm{L}$ 'ye ve kömür işleme atıksularında $3900 \mathrm{mg} / \mathrm{L}$ 'ye kadar ulaşabilmektedir [3]. Birçok fenol bileşiği, insan sağlığına toksik etki göstermesinden dolayı tehlikeli kirleticiler arasında sınıflandırılmıştır. Fenolün sucul ortamlarda $1 \mu \mathrm{g} / \mathrm{L}$ gibi düşük konsantrasyondaki mevcudiyeti bile sucul organizmalar üzerine toksik etki göstermektedir. Yüzeysel sulardan içme suyu arıtma tesislerine ulaşan ve buradan da insani tüketim amaçlı kullanılan sularda varlık gösterebilecek olan fenol ve türevleri, insan sağlığı açısından potansiyel bir tehdit oluşturur. Fenol kirliliği içeren suların insanlar tarafından tüketilmesi sonucunda şiddetli ağrılar, kılcal damar hasarı ve ölümler meydana gelebilmektedir. İçme sularında fenolün varlığı kötü tat ve kokuya sebep olmaktadır [4]. Atıksulardan fenol ve türevlerinin gideriminde adsorpsiyon, kimyasal oksidasyon, distilasyon, çöktürme, iyon değiştirme, membran prosesleri ve biyolojik parçalama yöntemleri kullanılmaktadır [1]. Yüksek fenol konsantrasyonu içeren atıksular biyolojik süreçlerde mikroorganizmalar üzerinde inhibisyon etkisi gösterebilmektedir. Atıksulardan fenol giderme yöntemleri arasında adsorpsiyon yöntemi, yüksek verimli çıkış suyu eldesi, kolay uygulama, çamur oluşturmama gibi özelliklerden dolayı ön plana çıkmaktadır [5]. Aktif karbon, yüksek yüzey alanından ve kaliteli çıkış suyu sağlamasından dolayı adsorpsiyon proseslerinde yaygın kullanılan bir adsorbenttir. Ancak bunun yanında aktif karbonun kömür gibi pahalı hammaddelerden elde edilmesi, bu malzemenin kullanımına sınır getirmektedir [6].
Manyetit $\left(\mathrm{Fe}_{3} \mathrm{O}_{4}\right)$, maghemit $\left(\gamma-\mathrm{Fe}_{2} \mathrm{O}_{3}\right)$ ve hematit $\left(\alpha-\mathrm{Fe}_{2} \mathrm{O}_{3}\right)$ gibi nano partiküller, spesifik büyülükte yüzey alanları, yüksek manyetizasyon doygunluğu ve oldukça fazla aktif sorpsiyon sitlerinden dolayı kirleticilerin atıksulardan adsorpsiyon yoluyla gideriminde kullanılmaları son yıllarda bilim dünyasında öne çıkan konular arasına girmiştir [7]. Manyetik nano partiküller manyetik özelliklerinden dolayı adsorpsiyon süreci sonunda manyetik bir alan uygulanarak atıksudan kolaylıkla ayrılabilmektedir. Manyetik nano partiküller aynı zamanda başka malzemelerde yüzey kaplayıcı olarak da kullanılmaktadır. Bu uygulama kaplanan malzemeyi yüzey alanı ve aktif sorpsiyon sitleri açısından iyileştirmekte ve malzemenin atıksuların aritılmasında adsorbent olarak kullanılabilme potansiyelini arttırabilmektedir [8]. Maghemit yeryüzünde bol miktarda bulunan bir mineraldir ve kübik spinal kristal yapıya sahiptir [9]. Maghemitin düşük maliyetler ile demir tuzlarından hava atmosferinde alkali şartlarda çöktürme işlemi ile kolaylıkla sentezlenebilmesi, bu malzemeyi adsorpsiyon süreçlerinde ön plana çıkarmaktadır.

Bu çalışmada sulu çözeltiden adsorpsiyon yolu ile fenol gideriminde, düşük maliyet ile elde edilmiş olan Eucalyptus camaldulensis/maghemit kompozitinin (ECMC) kullanım potansiyelinin araştırılması amaçlanmıştır. Eucalyptus kabukları, bol bulunan, yenilenebilir ve düşük maliyetli kaynak olmasından dolayı nano kompozit üretiminde ham madde olarak tercih edilmiştir.

\section{MATERYAL VE METOT}

\subsection{ECMC Eldesi}

Eucalyptus kabukları, Çukurova Üniversitesi Balcalı Kampüsündeki Eucalyptus camaldulensis ağaçlarından toplanmıştır. Kabuklar kir ve tozdan arındırılmak için distile su ile yıkanarak etüvde $60{ }^{\circ} \mathrm{C}$ 'de, 48 saat boyunca kurutulmuştur. Kabuklar 0,5-1 $\mathrm{mm}$ arasında olacak şeklide parçalanıp elek analizine tabi tutulmuştur. ECMC alkali şartlarda kimyasal çöktürme yöntemine göre elde edilmiştir. $5 \mathrm{~g}$ kabuk, $5,82 \mathrm{~g} \mathrm{FeCl}_{3} \cdot 6 \mathrm{H}_{2} \mathrm{O}$ ve $3 \mathrm{~g} \mathrm{FeSO} 4.7 \mathrm{H}_{2} \mathrm{O}$ toplam hacmi $1000 \mathrm{~mL}$ olacak şekilde distile suda 2 saat boyunca $70{ }^{\circ} \mathrm{C}$ 'de 
manyetik karıştırıcı ile güçlü bir şekilde karıştırılmıştır. Daha sonra $5 \mathrm{~N} \mathrm{NaOH}$ damla damla eklenerek siyah demir oksit partiküllerinin çökmesi sağlanmıştır. Bu işlemi takiben $100 \mathrm{~mL}$ $\% 65 \mathrm{HNO}_{3}$ eklenerek $80{ }^{\circ} \mathrm{C}$ 'de 4 saat süresinde güçlü bir şekilde karıştırma işlemi uygulanmıştır. $\mathrm{HNO}_{3}$ burada kalınt demir oksitleri, maghemite okside eden bir oksitleyici olarak kullanılmıştır. Son olarak elde edilen ürün distile su ile yıkanıp alkali kalıntılardan temizlenip $70{ }^{\circ} \mathrm{C}$ 'de 48 saat boyunca kurutulmuştur.

\subsection{Fenol Analizi}

Fenol tayini spektrofotometrik yöntemle gerçekleştirilmiştir. Fenol alkali ortamda potasyum ferrisiyanit varlığında 4-amino antipirin ile reaksiyona girerek turuncu bir renk oluşturur. Çözeltideki kalıntı fenol konsantrasyonu, oluşan rengin $500 \mathrm{~nm}$ dalga boyunda absorbsiyonuna dayalı olarak hazırlanan çalışma eğrisinden tespit edilmiştir.

\subsection{ECMC Karakterizasyonu}

Elde edilen ECMC'nin ve maghemitin morfolojik araştırması taramalı elektron mikroskopisi kullanılarak (SEM) gerçekleştirilmiştir. ECMC'nin ve ham kabuğun temel elementel bileşenleri ve yüzeysel modifikasyon değerlendirmesi enerji dağılımlı X-ışını (EDX) ile sağlanmıştır (FEI Quanta 650 Field Emission). ECMC'nin manyetik özellikleri süper iletken quantum magnometresi kullanılarak ortaya koyulmuştur (Quantum Design, PPMS DynaCool-9). Ham kabuk ve ECMC kristalin fazları X-ışını kırınımı difraktometresi (XRD) ile araştırılmıştır (PANalytical EMPYREAN XRD).

\subsection{Adsorpsiyon Çalışmaları}

Fenolün ECMC tarafindan adsorpsiyonla giderilmesi süreci üzerine temas zamanının $(5,10$, 20, 30, 40, 50, 60, 70, 80 ve $100 \mathrm{dk}), \mathrm{pH}$ 'in $(3,4$, $5,6,7,8,9$ ve 10$)$, çözelti sicaklığının $(10,15,20$, $25,30,35$ ve $\left.40{ }^{\circ} \mathrm{C}\right)$ ve başlangıç fenol konsantrasyonunun $(100,200,300400$ ve
$500 \mathrm{mg} / \mathrm{L}$ ) etkisi araştırılmıştır. Yapılan adsorpsiyon çalışması kesikli süreç olup, $500 \mathrm{~mL}$ erlenmayerlerde ve $250 \mathrm{~mL}$ hacminde sulu çözeltide 1 gram sabit ECMC dozu ile gerçekleştirilmiştir. Karıştırma işlemi 250 rpm'de, sıcaklık ayarlı çalkalayıcı ile sağlanmıştır. Tüm analizler 3 tekrarlı gerçekleştirilmiş olup hesaplamalarda ortalama değerler kullanılmıştır.

\section{BULGULAR VE TARTIŞMA}

\subsection{ECMC Karakterizasyonu}

\subsubsection{SEM}

Maghemit ve ECMC'nin SEM görüntüleri Şekil 1'de verilmiştir. Yapılan SEM analizleri, maghemit partiküllerinin homojen ve çok küçük parçacık yapısında olduğunu göstermiştir. Bunun yanında, ECMC yapısının ağaç kabuğu kaynaklı olmasından dolayı amorf bir yapıda olduğu gözlemlenmiştir.

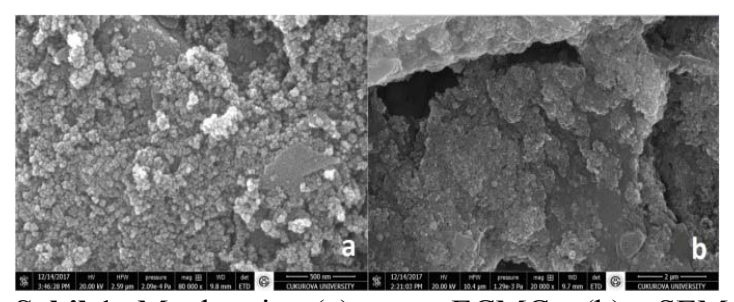
Şekil 1. Maghemit (a) ve ECMC (b) SEM
görüntüleri

\subsubsection{EDX}

E. camaldulenis kabuklarının ve ECMC'nin EDX analiz sonuçları Şekil 2'de verilmiştir. Yapılan analizler E. camaldulenis kabuklarının temel elementlerinin $\mathrm{C}, \mathrm{O}, \mathrm{Si}, \mathrm{Au}, \mathrm{Cl}, \mathrm{Ca}$ ve $\mathrm{Fe}$ olduğunu göstermiştir. Bunun yanında ECMC temel elementleri $\mathrm{C}, \mathrm{O}, \mathrm{Na}, \mathrm{Ca}, \mathrm{Fe}$ ve $\mathrm{Cu}$ olarak tespit edilmiştir E. camaldulenis kabuklarının ağırlıç̧a Fe elementi yüzdesi \%0,06 bulunurken, ECMC için ağırlıkça Fe elementi yüzdesi \%37,66 olarak bulunmuştur. $\mathrm{Bu}$ durum E. camaldulenis kabuklarının yüzeyinin maghemit ile başarılı bir şekilde kaplandığını göstermektedir. 


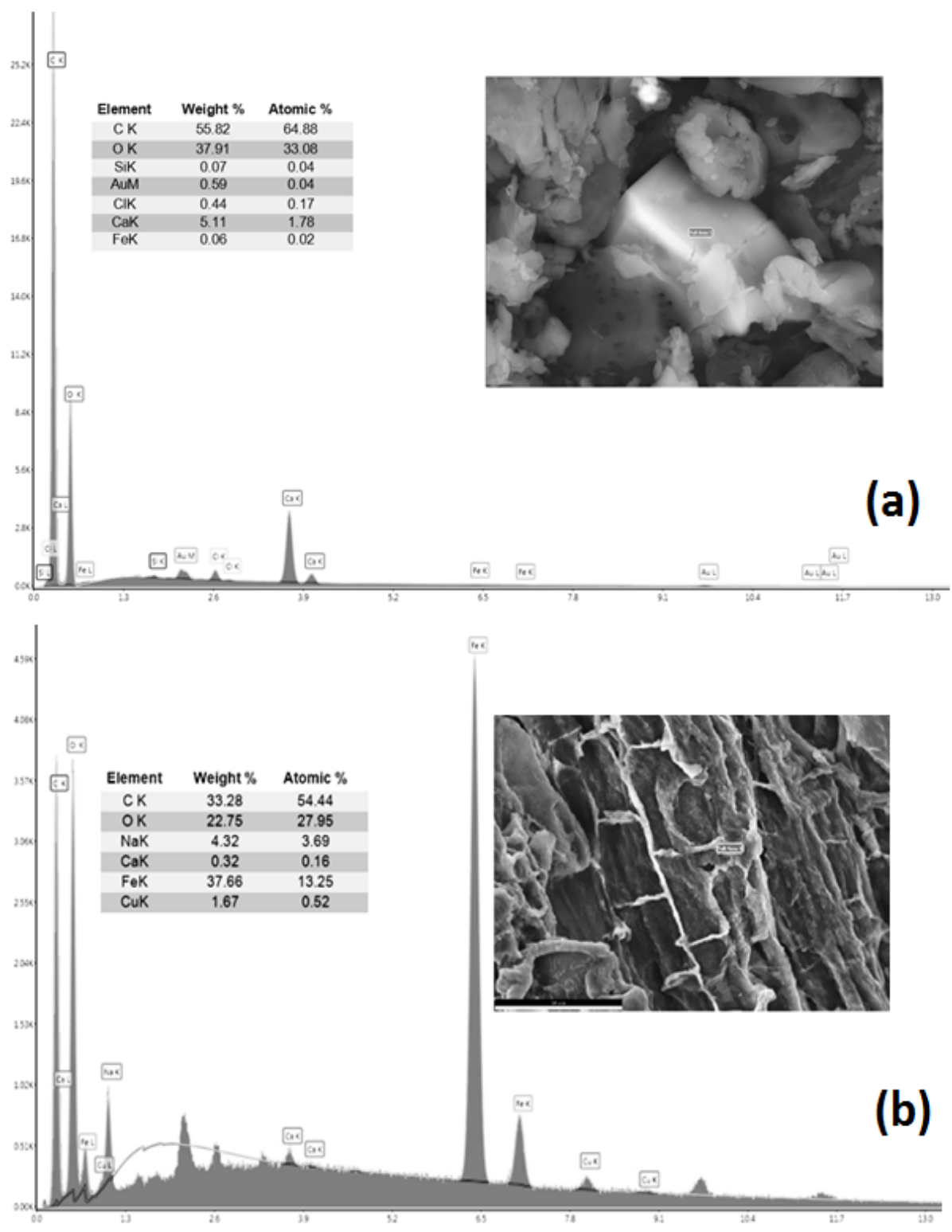

Şekil 2. Eucalyptus camaldulensis kabukları (a) ve ECMC (b) için EDX analizleri

\subsubsection{Manyetik Özellikler}

Nano manyetik adsorbentlerin manyetik doygunluğu, bu adsorbentlerin adsorpsiyon süreçlerinden sonra sıvı fazdan kolayca ayrılabilmesi için önemli bir parametredir. ECMC'nin manyetik analizi Şekil 3'te verilmiştir. Yapılan analizler sonucunda ECMC'nin manyetizasyon doygunluk değeri 60,11 emu/g olarak tespit edilmiştir. Elde edilen bu değer, ECMC'nin, manyetik alan uygulaması ile adsorpsiyon sürecinden sonra sıv1 fazdan kolayca ayrılabileceğini göstermektedir. Bu durum yüzeyin Fe elementi ile modifiye edilmesinin bir sonucu olarak ortaya çıkmaktadır. 


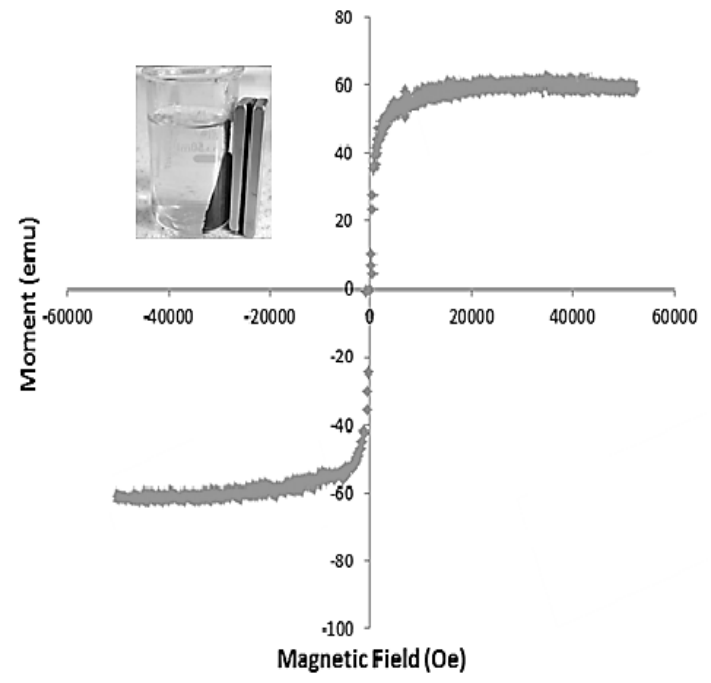

Şekil 3. ECMC manyetik özellikleri

\subsubsection{XRD}

Maghemit, Eucalyptus camaldulenis kabuğu ve ECMC için XRD analizleri Şekil 4'de verilmiştir. Maghemit için kübik spinal kristal yapısına bağlı olan belirgin kırınım pikleri $2 \theta=17,6$ (111), 25,43 (211), 28,95 (220), 34,35 (311), 38,26 (320), 39,08 (321) ve 42,04 (400) pozisyonlarında elde edilmiştir ve elde edilen malzemenin maghemit olduğu doğrulanmıştır. (Referans Card No: 98-024-9048). Bunun yanında Eucalyptus camaldulenis kabuğu için $2 \theta=15,04$ ve 22,38 'de iki geniş pik elde edilmiştir. Geniş pik yapısı malzemenin amorfluğuna ait bir gösterge olup bu ağacın doğal yapısından dolayı beklenen bir durumdur. ECMC için yapılan XRD analizlerinde ağaç kabuğuna ait piklerin yanı sıra maghemite ait pikler de elde edilmiştir, bu durum kabuğun yüzeyinin maghemit nano partikülleri ile etkili bir şekilde kaplandığını doğrulamaktadır.
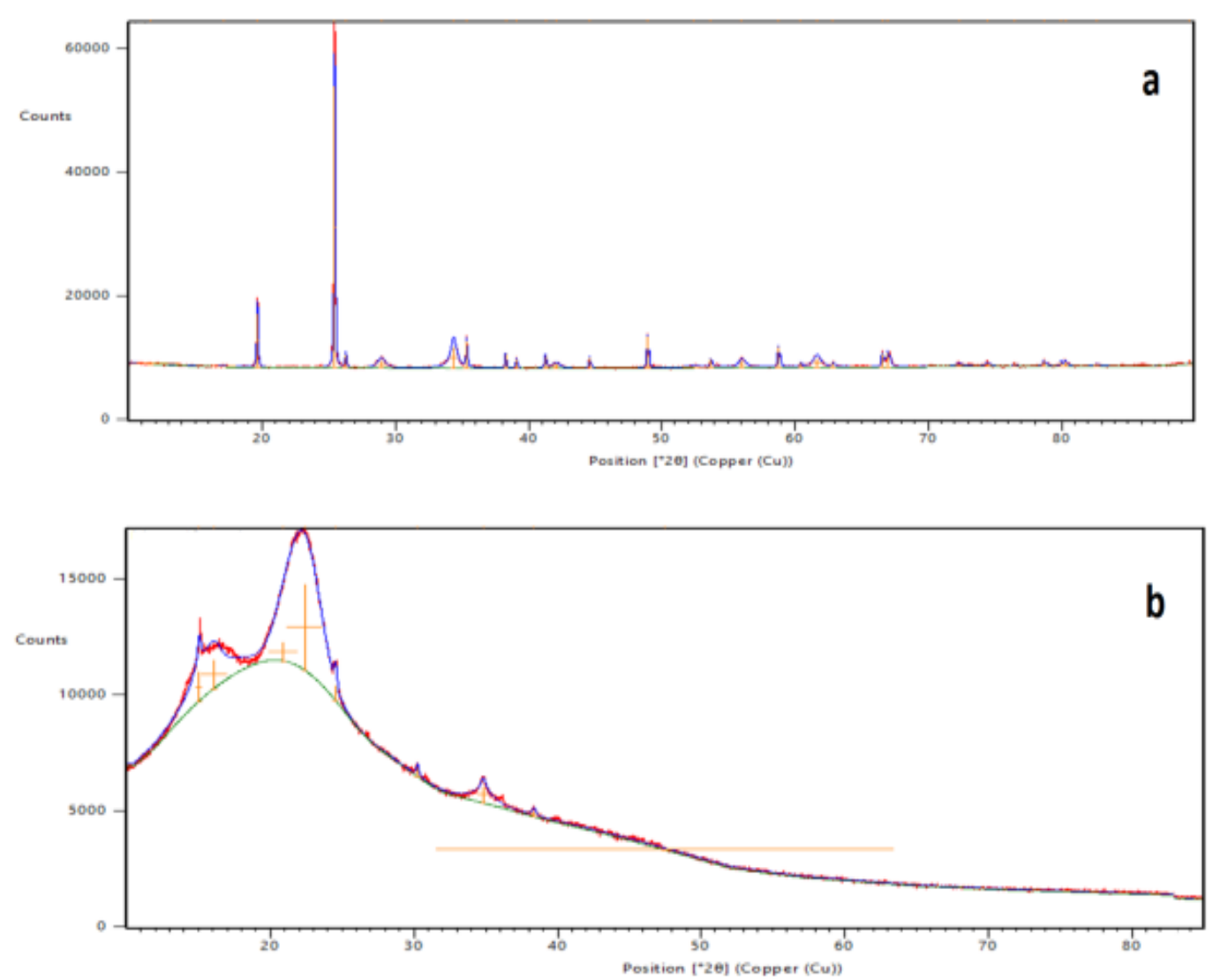


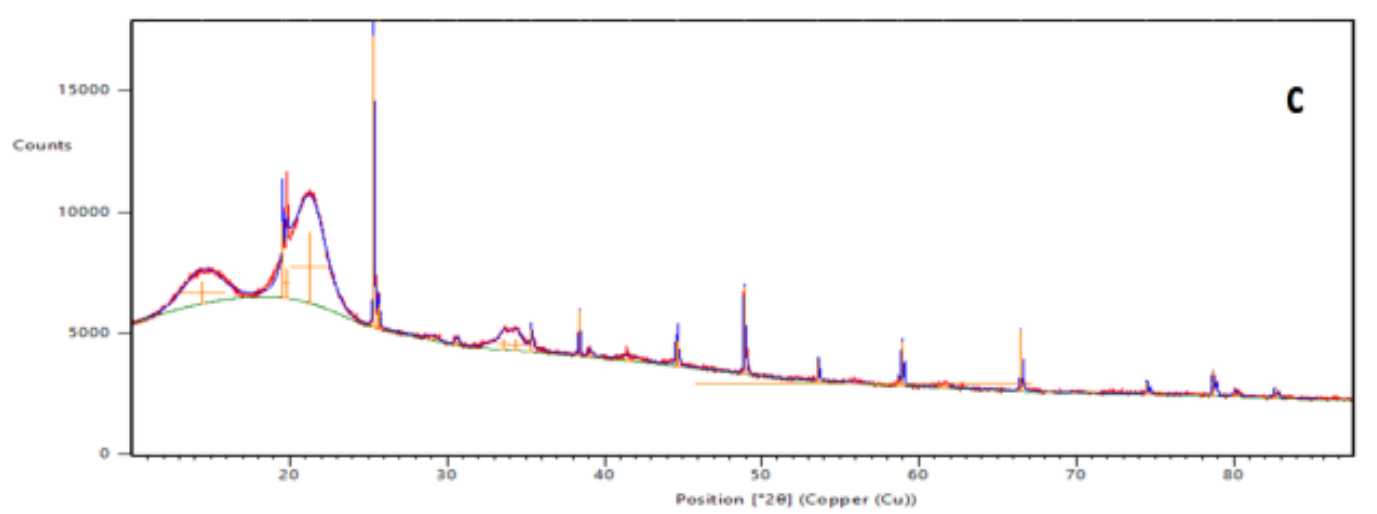

Şekil 4. Maghemit (a), E. camaldulensis kabuğu (b) ve ECMC (c) için XRD analizleri

\subsection{Adsorpsiyon Denge Zamanı}

Adsorpsiyon süreçleri denge tepkimeleri ile benzer yapıdadır. Sıvı fazdaki adsorbatın (tutunan madde) konsantrasyonu ile katı faz üzerinde tutulan adsorbatın konsantrasyonu dengeye ulaştığı zaman adsorpsiyon tamamlanır. Denge zamanını belirlemek için sabit sıcaklıkta, denge anına kadar katı fazın birim gramı üzerinde tutulan adsorbat miktarı $\left(\mathrm{q}_{\mathrm{t}}\right)$ zamana karşı grafiğe geçirilir [10]. Denge zamanındaki adsorbentin birim ağırlığında (g) adsorbe edilen adsorbat miktarı (mg) olan " $\mathrm{q}_{\mathrm{e}}$ " değerini tespit etmek gerekmektedir [11].

Adsorpsiyon denge zamanı çalışması $500 \mathrm{mg} / \mathrm{L}$ fenol için pH 7'de, $20^{\circ} \mathrm{C}^{\prime}$ de gerçekleştirilmiştir. Yapılan çalı̧̧mada adsorpsiyon denge zamanının 70 dk. olduğu tespit edilmiştir. Denge zamanında hesaplanan adsorpsiyon kapasitesi 74,125 mg/g'dır. Adsorpsiyon kapasitesi (q) Eşitlik 1 kullanılarak hesaplanmıştır. Adsorpsiyon denge grafiğgi Şekil 5'de verilmiştir.

$q=\frac{\left(C_{0}-C_{e}\right) V}{W}$

$q=$ Adsorpsiyon kapasitesi, $\mathrm{mg} / \mathrm{g}$

$C_{0}=$ Başlangıç fenol konsantrasyonu, $\mathrm{mg} / \mathrm{L}$

$C_{\mathrm{e}}=$ Çıkış fenol konsantrasyonu, $\mathrm{mg} / \mathrm{L}$

$V=$ Çözelti hacmi, $\mathrm{L}$

$W=$ Adsorbent kütlesi, $\mathrm{g}$

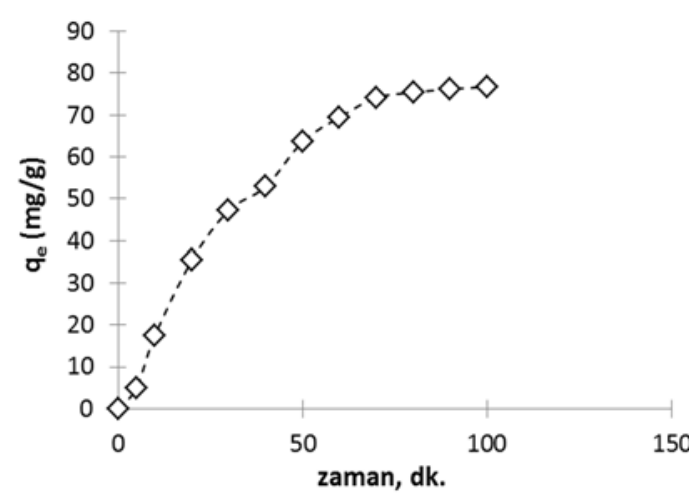

Şekil 5. Adsorpsiyon denge zamanı

\section{3. pH'm Etkisi}

pH'ın adsorpsiyon süreci üzerine olan etkisinin araştırılması, $500 \mathrm{mg} / \mathrm{L}$ fenol için, $20{ }^{\circ} \mathrm{C}$ 'de ve 1 gram ECMC dozu ile gerçekleştirilmiştir. Adsorbentin yüzeyi ile adsorbat arasındaki elektrostatik etkileşimler çözeltideki iyon konsantrasyonu ve ortamın pH'ına bağlı olarak değişebileceğinden, $\mathrm{pH}$ adsorpsiyon ile metallerin sıv1 fazdan giderimi üzerine önemli derecede etki gösterebilen parametrelerden biridir [12]. Adsorpsiyon kapasitesi üzerine $\mathrm{pH}^{\prime} \mathrm{in}$ etkisini gösteren grafik Şekil 6'da verilmiştir. Yapılan çalışmalar ECMC'nin en yüksek adsorpsiyon kapasitesine $\mathrm{pH} \quad 5$ 'te ulaştığını göstermiştir. $\mathrm{pH}$ 5'te ECMC'nin fenol için adsorpsiyon kapasitesi 90,92 mg/g bulunurken, $\mathrm{pH} 3$ ve 10'da sirasiyla 65,42 ve $38,6 \mathrm{mg} / \mathrm{g}$ olarak bulunmuştur. Fenol zayıf asit bir karakterde olup $\mathrm{pK}_{\mathrm{a}}$ değeri 
9,89'dur. $\mathrm{pK}_{\mathrm{a}}$ değerinin üzerindeki $\mathrm{pH}$ değerlerinde sıvı fazdaki fenolün iyon halinde bulunma yüzdesi artmaktadır. Bunun yanında $\mathrm{pH}$ değeri $\mathrm{pK}_{\mathrm{a}}$ değerinin altına indikçe çözeltideki fenolün moleküler halde bulunma yüzdesi artmaktadır. Fenolün moleküler halde bulunması adsorbent yüzeyine sorpsiyon eğilimini arttıran bir unsurdur. Yüksek $\mathrm{pH}$ değerlerinde elde edilen düşük adsorpsiyon kapasitelerinin, fenolün alkali şartlarda iyon yüzdesinin artması ve adsorpsiyonunun elverişliliğinin azalmasından kaynaklandığı düşünülmektedir. Bunun yanında, pH 3 ve 4'de fenolün pH 5'e göre daha fazla moleküler formda bulunması ve buna bağlı olarak daha çok adsorbe olması beklenirken, pH 3 ve 4'de adsorpsiyon kapasiteleri $\mathrm{pH}$ 5'e göre düşüş göstermiştir. $\mathrm{Bu}$ durum, düşük $\mathrm{pH}$ değerlerinde artan $\mathrm{H}^{+}$iyonlarının ECMC yüzeyinde bulunan adsorpsiyon sitlerini işgal etmesi ve fenol adsorpsiyonunu azaltması şeklinde açıklanabilir [13]. Tüm pH değerlerinde denge zamanının 60-70 dk civarı olduğu tespit edilmiştir. Optimum $\mathrm{pH}$ değeri olarak 5 seçilmiş ve sonraki çalışmalar bu $\mathrm{pH}$ değerinde gerçekleştirilmiştir.

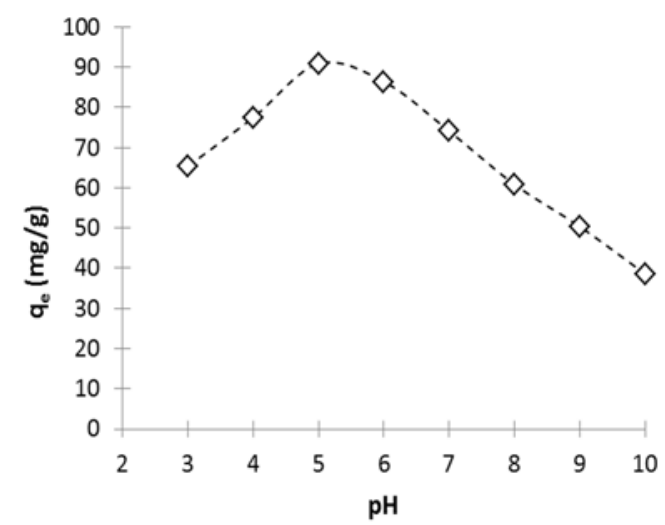

Şekil 6. Adsorpsiyon süreci üzerine pH'ın etkisi

\subsection{Sıcaklığın Etkisi}

Adsorpsiyon sürecine sicaklığın etkisinin araştırıldığ 1 deneysel süreç, $500 \mathrm{mg} / \mathrm{L}$ fenol konsantrasyonu, $\mathrm{pH} 5$ 'de ve 1 gram ECMC dozu ile gerçekleştirilmiştir. Yapılan çalışmalar, ECMC'nin fenol için adsorpsiyon kapasitesinin, sıcaklığı artmasıyla bir miktar arttığını göstermiştir. Adsorpsiyon kapasitesi $10{ }^{\circ} \mathrm{C}$ için
$87,8 \mathrm{mg} / \mathrm{g}$ bulunurken, $40{ }^{\circ} \mathrm{C}$ için $95,3 \mathrm{mg} / \mathrm{g}$ olarak tespit edilmiştir. Ekonomik uygulanabilirlik açısından optimum sıcaklık $20{ }^{\circ} \mathrm{C}$ olarak belirlenmiş ve sonraki deneyler bu sıcaklık değerinde gerçekleştirilmiştir.

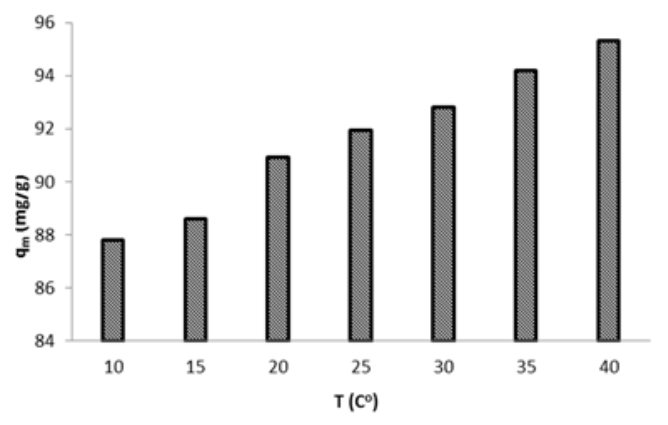

Şekil 7. Adsorpsiyon süreci üzerine sıcaklığın etkisi

\subsection{Fenol Konsantrasyonunun Etkisi}

Adsorpsiyon süreci üzerine fenol konsantrasyonunun etkisinin araştırılması için yapılan deneysel süreç $20^{\circ} \mathrm{C}$ 'de, $\mathrm{pH} 5^{\prime}$ 'de ve $1 \mathrm{~g}$ ECMC dozu ile gerçekleştirilmiştir. Yapılan çalışmalar, adsorpsiyon kapasitesinin, fenol konsantrasyonunun artmasıyla arttığını ve fenol konsantrasyonunun azalmasıyla azaldığını göstermiştir. Adsorpsiyon kapasiteleri 100 ve $500 \mathrm{mg} / \mathrm{L}$ fenol konsantrasyonları için sırasıyla; 22,1 ve $90,92 \mathrm{mg} / \mathrm{g}$ olarak hesaplanmıştır. Sulu çözeltideki başlangıç fenol konsantrasyonunun adsorpsiyon kapasitesi üzerine etkisini gösteren grafik Şekil 8'de verilmiştir.

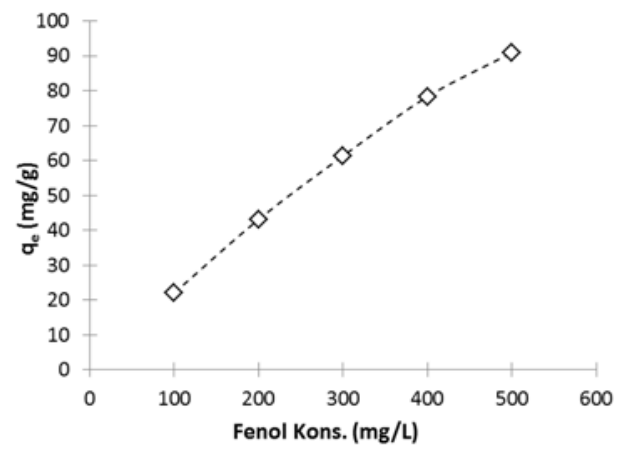

Şekil 8. Adsorpsiyon süreci üzerine fenol konsantrasyonunun etkisi 


\subsection{Adsorpsiyon İzotermleri}

Adsorpsiyon izotermleri, adsorpsiyon denge zamanına ulaşıı̆ı zaman adsorplanan moleküllerin katı ve sıvı faz arasında nasıl bir dağılım sergilediğini gösterir. Adsorpsiyon sürecinden elde edilen veri ile en iyi izoterm modellerinin elde edilmesi adsorpsiyon proseslerinin dizaynı için önemli bir adımdır [14]. Bu çalışmadan elde edilen bulgular en yaygın ve geçerli olan Langmuir ve Freundlich izotermlerine uygulanmıştır.

\subsubsection{Langmuir İzotermi}

$\mathrm{Bu}$ izoterm, adsorbent yüzeyinde adsorplayıcı noktaların olduğunu farz eder. Her adsorplayıcı noktanın bir molekül adsorplayacağını kabul ederek oluşan tabakanın bir molekül kalınlığında bir tabaka olacağını söyler. Denge halinde maksimum adsorpsiyon kapasitesine ulaşılmış ve yüzey tek tabakayla kaplanmış olur [15]. Langmuir eşitliğinin lineer hali Eşitlik 2'de verilmiştir

$$
\frac{C_{e}}{q_{e}}=\frac{C_{e}}{q_{\text {maks }}}+\frac{1}{K_{L} q_{\text {maks }}}
$$

$\mathrm{C}_{\mathrm{e}}$ : Adsorpsiyon sonrası çözeltide kalan maddenin konsantrasyonu $(\mathrm{mg} / \mathrm{L})$

$\mathrm{q}_{\mathrm{e}}$ : Birim adsorbent üzerine toplanan madde miktarı (mg/g)

$\mathrm{K}_{\mathrm{L}}$ : Adsorbatın adsorptivitesine bağlı olan sabit (L/mg)

qmaks: Adsorbentin maksimum adsorplama kapasitesi (mg/g)

$\mathrm{q}_{\text {maks }}$ ve $\mathrm{K}_{\mathrm{L}} \mathrm{C}_{\mathrm{e}} / \mathrm{q}_{\mathrm{e}}$ 'nin $\mathrm{C}_{\mathrm{e}}$ 'ye karşı grafiğge geçirilmesi ile elde edilen doğrunun eğiminden ve kesim noktasından hesaplanır.

\subsubsection{Freundlich İzotermi}

Freundlich, adsorpsiyon prosesini ifade eden ampirik bir denklem geliştirilmiştir. Freundlich'e göre bir adsorbentin yüzeyi üzerinde bulunan adsorpsiyon alanları heterojendir yani farklı türdeki adsorpsiyon alanlarından teşkil edilmiştir. Freundlich izoterminin lineer eşitliği Eşitlik 3 'te verilmiştir.

$\operatorname{loq} q_{e}=\log K_{F}+\frac{1}{n} \log C_{e}$

$\mathrm{K}_{\mathrm{F}}$, izoterm sabitini ( $\mathrm{L} / \mathrm{mg}$ ), $\mathrm{n}$ (birimsiz) ise adsorpsiyonun yoğunluğunu gösterir. $\mathrm{n}$ değeri 0 ile bir arasında değerler alır. $\mathrm{n}$ değerinin 0 'a yakınlığ 1 yüzey heterojenitesinin yoğunluğunun yüksek olduğunu gösterir [16]. $\mathrm{n}$ ve $\mathrm{K}_{\mathrm{F}}$ değerleri, $\log \mathrm{q}_{\mathrm{e}}$ 'nin $\log \mathrm{C}_{\mathrm{e}}$ 'ye karşı grafiğe geçirilmesi ile elde edilen doğrunun eğiminden ve kesim noktasından hesaplanır.

Langmuir izotermi 0,998 korelasyon katsayısı ile ECMC'ın fenol için adsorpsiyonundan elde edilen veriyi çok iyi bir şekilde tanımlamıştır. Langmuir izotermi ECMC'nin fenol için maksimum adsorpsiyon kapasitesini 127,96 mg/g olarak tahmin etmiştir. Tahmin edilen bu değer deneysel veri ile elde edilen adsorpsiyon kapasitesi ile uyum göstermektedir.

Langmuir izoterm sabiti olan $\mathrm{K}_{\mathrm{L}}$ değeri 2,28 1/mg olarak bulunmuştur. Bunun yanında Freundlich izotermi 0,982 korelasyon katsayıs ile adsorpsiyon sürecini orta derecede bir verimle açıklamıştır.

Freundlich heterojenite faktörü olan " $n$ " değeri 0,506 olarak bulunmuştur. " $n$ " değerinin $0-1$ arasından bir değer olarak tespit edilmesi ECMC ile fenol adsorpsiyonunun elverişli bir süreç olduğunu göstermektedir. Çizelge 1'de farklı adsorbentlerin fenol için benzer şartlar altında elde edilmiş olan maksimum adsorpsiyon kapasiteleri verilmiştir. Çizelge 1'den de anlaşılacağ gibi ECMC diğer adsorbentlere göre genel olarak yüksek bir adsorpsiyon kapasitesi sergilemektedir. $\mathrm{Bu}$ durum ECMC'in sivi fazdan fenolün adsorpsiyon ile gideriminde, oldukça elverişli bir adsorbent olduğunu göstermektedir. 
Çizelge 1. Literatür karşılaştırması

\begin{tabular}{|l|l|c|c|}
\hline Adsorbent & İoterm & $\begin{array}{c}\text { Maks. Ads. } \\
\text { Kapasitesi } \\
\text { (mg/g) }\end{array}$ & Kaynak \\
\hline $\begin{array}{l}\text { Akrilonitril/etilen } \\
\text { glikol dimetakrilat } \\
\text { polimeri }\end{array}$ & Langmuir & 22,2 & {$[17]$} \\
\hline $\begin{array}{l}\text { NiFe } \mathrm{O}_{4} / \text { Toz Aktif } \\
\text { Karbon Kompoziti }\end{array}$ & Langmuir & 93,25 & {$[18]$} \\
\hline Silika aerojel & Langmuir & 7,0 & {$[19]$} \\
\hline $\begin{array}{l}\text { Hindistan cevizi } \\
\text { kabuğu kökenli } \\
\text { aktif karbon }\end{array}$ & Langmuir & 122,18 & {$[20]$} \\
\hline $\begin{array}{l}\text { Dowex Optipore } \\
\text { L493 Polimeri }\end{array}$ & Langmuir & 78,77 & {$[21]$} \\
\hline $\begin{array}{l}\text { Zeolit-Aktif } \\
\text { Karbon Kompoziti }\end{array}$ & Langmuir & 37,92 & {$[22]$} \\
\hline Karbon Nano Tüp & Langmuir & 64,60 & {$[23]$} \\
\hline $\begin{array}{l}\text { Manyetik Geri } \\
\text { Kazanılabilir } \\
\text { Karbon }\end{array}$ & Langmuir & 123,45 & {$[24]$} \\
\hline $\begin{array}{l}\text { Manyetik Demir } \\
\text { Oksit/Karbon Nano } \\
\text { Kompozit }\end{array}$ & Langmuir & 19,35 & {$[25]$} \\
\hline $\begin{array}{l}\text { Yumurta Kabuğu } \\
\text { Kökenli Aktif } \\
\text { Karbon }\end{array}$ & Langmuir & 191.87 & {$[26]$} \\
\hline $\begin{array}{l}\text { Multi Wall Karbon } \\
\text { Nano Tüp }\end{array}$ & Langmuir & 32,25 & {$[27]$} \\
\hline Bentonit & Langmuir & 66,67 & {$[28]$} \\
\hline Doğal Zeolit & Langmuir & 35,5 & {$[29]$} \\
\hline $\begin{array}{l}\text { Azotla } \\
\text { Zenginleștirilmiş } \\
\text { Aktif Karbon }\end{array}$ & Langmuir & 167 & Bu Çalışma \\
\hline ECMC & Langmuir & $\mathbf{1 2 7 , 9 6}$ & \\
\hline
\end{tabular}

\section{SONUÇ VE ÖNERÍLER}

Bu çalışmada Eucalyptus camaldulensis/maghemit kompoziti ile sulu çözeltiden değişen parametreler altında, fenolün adsorpsiyon yolu ile giderimi araştırılmıştır. Yapılan çalışmalar adsorpsiyon süreci üzerine temas zamanının, $\mathrm{pH}$ 'ın ve başlangıç fenol konsantrasyonunun önemli derecede etki ettiğini göstermiştir. Bunun yanında elde edilen bulgular sicaklık parametresinin adsorpsiyon süreci üzerine önemli bir etki göstermediğini ortaya koymuştur. $500 \mathrm{mg} / \mathrm{L}$ fenol için ECMC'nin adsorpsiyon kapasitesinin, $\mathrm{pH} 5$ 'de, $20^{\circ} \mathrm{C}$ 'de ve 1 gram ECMC dozu ile $90,92 \mathrm{mg} / \mathrm{g}$ olduğu bulunmuştur. Langmuir izotermi, 0,998 korelasyon katsayısı ile ECMC'nin fenol için maksimum adsorpsiyon kapasitesini $127,96 \mathrm{mg} / \mathrm{g}$ olarak tahmin etmiştir. Yapılan çalışmalar Eucalyptus camaldulensis/maghemit kompoziti ile fenolün sulu çözeltiden adsorpsiyon ile başarılı bir şekilde giderilebildiğini göstermiştir.

\section{KAYNAKLAR}

1. Busca, G., Berardinelli, S., Resini, C., Arrighi, L., 2008. Technologies for the Removal of Phenol from Fluid Streams: a Short Review of Recent Developments, J. Hazard. Mater., 160, 265-288.

2. Moussavi, G., Mahmoudi, M., Barikbin, B., 2009. Biological Removal of Phenol from Strong Wastewaters Using a Novel MSBR. Water Res., 43, 1295-1302.

3. Mohammadi, S., Kargari, A., Sanaeepur, H., Abbassian, K., Najafi, A., Mofarrah, E., 2014. Phenol Removal from Industrial Wastewaters: A Short Review, Desalin. Water Treat., 1-20

4. Mostafa, M.R., Sarma, S.E. and Yousef, A.M., 1998. Removal of Organic Pollutants from Aqueous Solution: Part 1. Adsorption of Phenols by Activated Carbon, Idian Journal of Chem., 28A, 946-948.

5. Ahalya, N., Ramachandra, T.V., Kanamadi, R.D., 2003. Biosorption of Heavy Metals, Res. J. Chem. Environ., 7, 71-78

6. Tamer, M.A., Ismail, A., Mohd, A.A., Ahmad, A.F., 2013. Cadmium Removal from Aqueous Solution Using Microwaved Olive Stone Activated Carbon, J. Environ. Chem. Eng., 1(5), 89-99.

7. Kang, H., Kim, D., 1998. Transformation of Nanoparticle Magnetite Prepared in Homogeneous Aqueous Solution, Bull. Korean Chem. Soc., 19, 408-410.

8. Nethaji, S., Sivasamy, A., Mandal, A.B., 2013. Preparation and Characterization of Corn Cob Activated Carbon Coated with Nano-Sized Magnetite Particles for the Removal of $\mathrm{Cr}(\mathrm{VI})$, Bioresource Technology, 134, 94-100.

9. Shokrollahi, H., Janghorban, K., 2007. Influence of Additives on the Magnetic Properties, Microstructure and Densification of Mn-Zn Soft Ferrites, Mater. Sci. Eng.: B, 141, 91-107.

10. Aksu, A., Sag, Y., Nourbakhsh, M., Kutsal. T., 1993. Atıksulardaki Bakır, Krom ve Kurşun İyonlarının Çeşitli Mikroorganizmalarla Adsorplanarak Giderilmesinin Karşılaştırmalı Olarak İncelenmesi, Turkish Journal of Engineering \& Environmental Sciences, 19, 285-29. 
11. Guptaa, S.S., Krishna, G.B, 2011. Kinetics of Adsorption of Metal Ions on Inorganic Materials: A Review, Advances in Colloid and Interface Science, 162(1-2), 39-5.

12. Behzad, H., Susana, R.C., Mohammad, A.A., Mohammad, A., Inderjee, T.T., Shilpi, A., Vinod, K.G., 2015. Kinetics and Thermodynamics of Enhanced Adsorption of the Dye AR 18 using Activated Carbons Prepared from Walnut and Poplar Woods, J. Mol. Liq., 208, 99-105.

13. Dabrowski, A., Podkos'cielny, P., Hubicki, Z., Barczak, M., 2005. Adsorption of Phenolic Compounds by Activated Carbon - a Critical Review, A. Chemosphere, 58, 1049-1070

14. Allen, S.J., Mckay, G., Porter, J.F., 2004. Adsorption Isotherm Models for Basic Dye Adsorption by Peat in Single and Binary Component Systems, Journal of Colloid and Interface Science, 280(2), 322-333.

15. Benefield, L.D., Judkins, J.F., Weand, B.L., 1982. Process Chemistry for Water and Wastewater Treatment, Prentice-Hall, Inc, Englewood Cliffs, New Jersey.

16. Chiou, M.S., Li, H.Y., 2002. Equilibrium and Kinetic Modeling of Adsorption of Reactive Dye on Cross-Linked Chitosan Beads, Journal of Hazardous Materials, 93(2), 233-248.

17. José, A.G.A., Juana, D.S.J., Maribel, LB., Manuel, S.C., Jenaro, L.V.C., 2017. Synthesis and Characterization of AN/EGDMA-Based Adsorbents for Phenol Adsorption, Reactive and Functional Polymers, 117, 112-119

18. Changmai, M., Purkait, M.K., 2017. Kinetics, Equilibrium and Thermodynamic Study of Phenol Adsorption using $\mathrm{NiFe}_{2} \mathrm{O}_{4}$ Nanoparticles Aggregated on PAC, Journal of Water Process Engineering, 16, 90-97.

19. Joana, M., Telma, M., Artur, J.M.V., António, P., Margarida, J.Q., Licínio, G.L., 2017. Adsorption of Phenol on Silica Aerogels using a Stirred Tank and a Fixed Bed Column, Ciência \& Tecnologia dos Materiais, 29, 229-233.

20. Rama, R.K., Sahub, J.N., Jayakumar, N.S., 2017. Optimal Isotherm Parameters for Phenol Adsorption from Aqueous Solutions onto Coconut Shell Based Activated Carbon: Error Analysis of Linear and Non-linear Methods,
Journal of the Taiwan Institute of Chemical Engineers, 80, 472-487.

21. Idil, I., Nalan, K., Mithat, Y., 2017. Separation of Bisphenol A and Phenol from Water by Polymer Adsorbents: Equilibrium and Kinetics Studies, Journal of Water Process Engineering, 16, 206-211.

22. Wen, P.C., Wei, G., Xinyu, C., Jing, H., Rui, F. L., 2016. Phenol Adsorption Equilibrium and Kinetics on Zeolite X/Activated Carbon Composite, Journal of the Taiwan Institute of Chemical Engineers, 62, 192-198.

23. Mohammad, H.D., Masoome, M., Mahmood, A., Gordon, M., Kaan, Y., Ahmad, B.A., Behzad, H., Mohammad, A., Mubarak, N.M, Sahu, J.N., 2016. High-performance Removal of Toxic Phenol by Single-Walled and MultiWalled Carbon Nanotubes: Kinetics, Adsorption, Mechanism and Optimization Studies, Journal of Industrial and Engineering Chemistry, 35, 63-74.

24. Babak, K., Mahsa, J., Mohammad, R., Amirhosein, R, Ali, A.B., 2016. Development of Response Surface Methodology for Optimization of Phenol and P-chlorophenol adsorption on Magnetic Recoverable Carbon, Microporous and Mesoporous Materials, 231, 192-206.

25. Roxana, I., Marcela, S., Cornelia, P., Cosmin, L., 2016. Single and Simultaneous Adsorption of Methyl Orange and Phenol onto Magnetic Iron Oxide/Carbon Nanocomposites, Arabian Journal of Chemistry, 535, 1-17.

26. Liliana, G., Juan, C.M., 2014. Study of Adsorption of Phenol on Activated Carbons Obtained from Eggshells. Journal of Analytical and Applied Pyrolysis, 106, 41-47.

27. Nour, T.A., Ghadir, A.E., Farag, S.H., 2015. Individual and Competitive Adsorption of Phenol and Nickel onto Multiwalled Carbon Nanotubes, Journal of Advanced Research, 6(3), 405-415.

28. Hank, D., Azi, Z., Ait, H.S., Chaalal, O., Hellal, A., 2014. Optimization of Phenol Adsorption onto Bentonite by Factorial Design Methodology, Journal of Industrial and Engineering Chemistry, 25, 2256-2263.

29. Rushdi, I.Y., Bassam, E., Ala'a, H.A., 2011. Adsorption Characteristics of Natural Zeolites 
as Solid Adsorbents for Phenol Removal from Aqueous Solutions: Kinetics, Mechanism, and Thermodynamics Studies, Chemical Engineering Journal, 171, 1143-1149.

30. Lorenc-Grabowska, E., Gryglewicz, G., Diez, M.A., 2014. Kinetics and Equilibrium Study of Phenol Adsorption on Nitrogen-enriched Activated Carbons, Fuel, 114, 235-243. 
